Risk of pulmonary embolism (PE) is relatively high in patients with advanced chronic diseases, particularly with malignancies. Most patients with cancer have blood coagulation test abnormalities indicative of up-regulation of the coagulation cascade, increased platelet activation and aggregation. Pulmonary thromboembolism is common in patients with any cancer and incidence is increased by surgery, chemotherapy, radiotherapy and disease progression. Manifestations range from small asymptomatic to life-threatening central PE with subsequent hypotension and cardiogenic shock. Diagnostic algorithms utilizing various noninvasive tests have been developed to determine the pretest probability of $P E$ results of D-dimer assay, chest radiography ECG and computed tomography. The mortality in untreated PE is high (30\%) but appropriate treatment may decrease it to $2-18 \%$. The current recommended treatment for massive pulmonary embolus is either thrombolytic therapy or surgical embolectomy.

Key words: embolus, cancer, thrombosis.

\section{Acute pulmonary embolus in the course of cancer}

\author{
Marta Biedka ${ }^{12}$, Ewa Ziółkowska², Wiesława Windorbska ${ }^{3}$
}

${ }^{1}$ Chair and Clinic of Oncology and Brachytherapy, Ludwik Rydygier Collegium Medicum, Bydgoszcz, Nicolaus Copernicus University, Toruń, Poland

2Radiotherapy Department I, The Franciszek Lukaszczyk Oncology Centre, Bydgoszcz, Poland

${ }^{3}$ Department of Teleradiotherapy, The Franciszek Lukaszczyk Oncology Centre, Bydgoszcz, Poland

\section{Introduction}

Venous thromboembolism includes two closely related disease entities: deep vein thrombosis and pulmonary embolism (PE). In one third of patients venous thrombosis is accompanied by symptomatic $P E$, while in the remaining patients only the former occurs. The risk of thromboembolic disease is observed in case of mutations in genes encoding proteins of the coagulation system, congenital vascular malformations and acquired hypercoagulable states. The most important acquired factors include surgical treatment, oral contraceptives, hormone replacement therapy and cancer [1-3].

Individuals with active cancer who have undergone surgery, particularly in the abdominal cavity or the small pelvis, are subject to 3-5 fold higher risk of thromboembolism, which is affected by the cancer itself, as well as age, obesity, duration of surgery, long recovery, radiotherapy and systemic therapy. Chemotherapy and hormone therapy can cause both venous and arterial thrombosis. Factors influencing incidence include the type of cancer and its stage, type of chemotherapy, its duration, response to therapy (tumor lysis syndrome), nutritional status, patient mobility, and functional efficiency of liver and kidney [1, 3].

Whether thromboembolic disease is symptomatic or not, its occurrence in a patient with cancer is about $15 \%$ and the risk of death within 6 months increases from $15 \%$ to $80 \%$ in case of thromboembolism. It is estimated that it is the second cause of death among cancer patients [4].

The objective of this article is to indicate problems that may arise during the diagnostic and therapeutic procedure in patients with cancer and PE.

\section{Risk factors}

The coagulation activation state in cancer has a multifactorial background. Tumors may express prothrombotic molecules. Some cancer cells produce substances such as cysteine proteases and/or serine, which directly contribute to clotting by activating factor $X$. It is also possible for the tumor to produce physiological tissue factor (TF), which is responsible for activation of the extrinsic pathway of blood coagulation. Cancer cells can also promote clotting indirectly, by secreting tumor necrosis factor and interleukin-like proteins that act on endothelial cells and mononuclear cells, stimulating secretion of prothrombotic molecules, which may in turn play a role in platelet activation (Tables 1, 2) [4].

\section{Clinical picture}

Clinical presentation of PE is often nonspecific. Its typical symptoms are shortness of breath, chest pain, fainting, hemoptysis and cough. The symptoms may often suggest a respiratory infection, cancer progression or com- 
Table 1. Risk factors for VTE according to the British Thoracic Society

\begin{tabular}{|c|c|}
\hline High & Low \\
\hline 1. Surgical procedures in the abdominal cavity & 1. Congenital heart defect \\
\hline 2. Surgery in the small pelvis & 2. Congestive heart failure \\
\hline 3. Hip and knee replacement & 3. Hypertension \\
\hline 4. Advanced pregnancy, puerperium & 4. Superficial vein thrombosis \\
\hline 5. Caesarean section & 5. The presence of central venous catheter \\
\hline 6. Fracture & 6. Oral contraception \\
\hline 7. Cancer & 7. Hormone replacement therapy \\
\hline 8. Immobilization & 8. Chronic obstructive pulmonary disease \\
\hline \multirow[t]{9}{*}{ 9. Episode of VTE in first interview first episode of VTE } & 9. The presence of neurological deficits \\
\hline & 10. Blood clotting disorders \\
\hline & 11. Immobilization due to a long journey \\
\hline & 12. Obesity \\
\hline & 13. Chronic inflammatory bowel disease \\
\hline & 14. Nephrotic syndrome \\
\hline & 15. Chronic dialysis \\
\hline & 16. Myeloproliferative diseases \\
\hline & 17. Paroxysmal nocturnal hemoglobinuria \\
\hline
\end{tabular}

Table 2. Risk factors for VTE according to the Polish Cardiological Society

\begin{tabular}{|c|c|}
\hline Primary & Secondary \\
\hline 1. Antithrombin deficiency & 1. Injuries, fractures \\
\hline 2. Congenital dysfibrinogenemia, hyperhomocysteinemia & 2. Stroke \\
\hline 3. The presence of anticardiolipin antibodies & 3. Advanced age \\
\hline 4. An excess of plasminogen activator inhibitor & 4. The presence of central venous catheter \\
\hline 5. Prothrombin 20210A mutation & 5. Chronic venous insufficiency \\
\hline 6. Protein C deficiency & 6. Smoking \\
\hline 7. Gene mutation of factor $V$ Leiden & 7. Pregnancy, puerperium \\
\hline 8. Plasminogen deficiency & 8. Crohn's disease \\
\hline 9. Protein $\mathrm{S}$ deficiency & 9. Nephrotic syndrome \\
\hline \multirow[t]{11}{*}{ 10. Factor XII deficiency } & 10. Excessive blood viscosity \\
\hline & 11. Abnormal function of platelets \\
\hline & 12. Surgical procedures \\
\hline & 13. Immobilization \\
\hline & 14. Cancer, chemotherapy \\
\hline & 15. Obesity \\
\hline & 16. Heart failure \\
\hline & 17. Long lasting journey \\
\hline & 18. Oral contraception \\
\hline & 19. Lupus anticoagulant \\
\hline & 20. Vascular grafts \\
\hline
\end{tabular}

plication of chemotherapy and radiotherapy. In 5-10\% of cases coronary pain occurs [5].

A physical examination of the patient most often reveals tachycardia, tachypnea, and nonspecific auscultatory changes over lung fields. There may be features of right heart failure-jugular vein congestion. Only $1 / 3$ of patients have clinical signs of coexisting venous thrombosis. The clinical picture and course of acute PE depend on the number and diam- 
eter of the choked arteries, and cardiorespiratory fitness. Sometimes the first symptom of PE is a sudden cardiac arrest, rarely full-blown pulmonary edema.

The diagnosis of PE may be hampered by the presence of lung metastases and lung injury secondary to oncological treatment: radiotherapy and/or chemotherapy. Moreover, clinical symptoms and radiological features of PE are usually not specific enough to distinguish it in the course of venous thromboembolism from embolism caused by tumor material. Gastric cancer is the most common cancer-related source of microemboli to the lung. Among the less frequent foci of primary PE there are tumors located in the bronchial tube, mammary gland, prostate and pancreas [6].

\section{Diagnostics}

The diagnosis of PE on the basis of only the clinical picture is difficult. Clinical suspicion of this complication requires the inclusion of anticoagulant therapy with simultaneous diagnostics aimed at reaching the correct diagnosis. Examinations which may prove useful include ECG, chest imaging study (X-rays, spiral CT, angio-CT), serum D-dimer levels, and gasometry.

\section{Coagulation abnormalities}

Most patients with cancer have blood coagulation test abnormalities indicative of up-regulation of the coagulation cascade, increased platelet activation and aggregation, and increased proteolysis. The complex mechanisms responsible for this activation may include release of cancer procoagulants, activation of host cells (such as monocytes or endothelial cells), overexpression of plasminogen activator inhibitor-1 (PAI-1), and altered expression or activity of proteins produced by the liver, including protein $C$ and anti-thrombin (AT).

Chemotherapeutic agents may also contribute to hypercoagulability by enhancing the release of procoagulants and cytokines from tumor cells, producing toxic substances, such as oxygen free radicals, that can damage the endothelium, and reducing levels of natural anticoagulants, such as proteins $C$ and $S$, and AT.

Determination of D-dimer is of limited clinical utility because of its low specificity (sensitivity $79-100 \%$, specificity $25-100 \%)$. It is used to exclude the presence of thromboembolism (negative), as a positive result may only suggest the possibility of thrombosis. In addition, elevated levels of D-dimer are observed in cases associated with the formation or dissolution of fibrin, that is the processes present in patients with cancer, infections, heart and kidney failure, sepsis and leukocytosis as well as in the elderly, which discriminates against this marker as a useful tool in the diagnosis of PE in patients with cancer $[4,6]$.

\section{Chest radiography}

Chest $\mathrm{X}$-ray examination does not confirm or exclude PE. In approximately $50 \%$ of patients abnormalities can be found, such as enlargement of the intermediate artery, cardiac enlargement (especially of the right ventricle), widened contour of the pulmonary trunk, and elevation of the diaphragm on the side of the embolism [3]. Sometimes Westermark sign can be observed. Patients with lung infarction are found to produce hydrothorax, frequently sanguineous. Parenchymal density, especially in patients with severe dyspnea or febrile patients, may be misinterpreted as atypical inflammatory changes. Radiological examination does not always allow the diagnosis of PE, but it enables us to exclude other diseases with similar clinical symptoms $[5,6]$.

\section{Tomography of the chest}

Spiral CT of the chest or angio-CT is now a fundamental and widely used method for the detection of PE. It consists in demonstrating the areas in the arteries which are not enhanced, despite the high saturation of pulmonary arterial blood, by contrast medium administered into a peripheral vein. This method allows the detection of even small thrombi in small vessels below the segmental artery. The widespread use of CT favors less frequent use of angiography for diagnostic purposes, which remains the gold standard in diagnosis of PE $[5,7,8]$.

\section{Other imaging modalities}

Catheter pulmonary angiography and nuclear medicine ventilation-perfusion (V/Q) scanning are both declining in use. Angiography, while historically considered the gold standard, has shown poor interobserver reliability for subsegmental clots and remains an invasive procedure. Catheter pulmonary angiography has been regarded as the gold standard for imaging PE due to its high negative predictive value. Although complications with this technique are rare, it is still an invasive procedure. Before widespread use of CT, ventilation-perfusion (VQ) scintigraphy was the test of choice to screen for PE. The major limitation lies in the very low specificity achieved when a high sensitivity is desired. The V/Q scan remains clinically unsatisfactory as most scans are of intermediate or indeterminate probability ( $73 \%$ of all performed), the specificity of a low probability examination is $10 \%$, and interobserver correlation is poor.

Because duplex venous ultrasound is a relatively easy study to perform and interpret, some authors have advocated bilateral lower extremity studies early in the algorithm for the work-up of PE. The rationale for this test is that deep venous thrombosis and PE are treated the same and that a positive result would obviate the need for further imaging [9].

Magnetic resonance angiography (MRA) has played a limited role in the evaluation of PE because of limited spatial resolution, motion artifact from respiration and cardiac activity, and long acquisition time. However, new ultrafast scanning techniques allow MRA acquisitions in 4 to 30 seconds with diagnostic accuracy approaching MDCT (multidetector computed tomography) and may play an increasing role in evaluating patients with contrast allergy or renal insufficiency [8].

\section{Arterial blood gas test}

The arterial blood gas test is intended only to assess respiratory function. The most common disorders are hypoxemia with hypocapnia and respiratory alkalosis. 


\section{Electrocardiogram}

Electrocardiographic changes are usually a dynamic process. The most common ECG changes are tachycardia, atrial fibrillation and supraventricular tachycardia. Occasionally there are non-specific changes in ST-T segment and negative T waves in leads V2-V4. Characteristic changes such as S1Q3T3 pattern or incomplete right bundle branch block do not often occur in acute PE. Normal ECG is seen in approximately $17 \%$ of patients with massive PE [6].

\section{Echocardiography}

Pulmonary embolism is associated with right ventricular overload. The changes observed in this study include right ventricular enlargement and RV hypokinesis, enlargement of the pulmonary trunk, paradoxical septal motion, ejection fraction, tricuspid insufficiency, widening of the inferior vena cava, and thrombus in the right ventricle and/or the atrium [6].

\section{Treatment}

The primary method of treatment of venous thromboembolism is administering anticoagulants and antifibrinolytics. In the initial treatment of non-massive PE it is recommended to use unfractionated heparin or low molecular weight heparin two times daily by subcutaneous injection. This treatment prevents the accumulation of thrombi, allowing vascular recanalization through the endogenous fibrinolytic system. Most commonly used is unfractionated heparin in a starting bolus dose of $80 \mathrm{lU} / \mathrm{kg}$ of body weight mc administered intravenously, and then by infusion according to normogram, on average $18 \mathrm{lU} / \mathrm{kg} / \mathrm{h}$. Activated partial thromboplastin time (APTT) should be 1.5-2.5 times longer than the norm. Despite the inconvenience of administration of unfractionated heparin it is the recommended form of treatment in acute PE. Apart from that intravenous antifibrinolytic treatment can be used according to the scheme: streptokinase 1.5 million units/h, or t-PA (alteplase) 100 mg/h. A new drug used in this disease unit is fondaparinux (a synthetic pentasaccharide richly sulfurized) administered subcutaneously every 24 hours. Its advantage is the $100 \%$ bioavailability and no need for coagulation monitoring. Patients with massive PE, hypotension or shock should be promptly and strictly treated with fibrinolytics (1.5 million units of streptokinase over 2 hours, t-PA (alteplase) 100 mg over 2 hours), or undergo embolectomy [9]. After completion of fibrinolytic treatment intravenous unfractionated heparin should be administered in a bolus dose of 80 units/kg followed by 18 units $/ \mathrm{kg} /$ hour infusion, on average 30000 units/day with aPTT monitoring. Also, low molecular weight heparin enoxaparin $1.5 \mathrm{mg} / \mathrm{kg} /$ day or $1 \mathrm{mg} / \mathrm{kg} /$ twice a day subcutaneously, nadroparin $0.1 \mathrm{ml}$ $10 \mathrm{~kg} /$ twice daily (9500 anti-Xa IU/ml) or $0.1 \mathrm{ml} / 10 \mathrm{~kg} /$ once daily (19 000 anti Xa IU/ml) or dalteparin $100 \mathrm{IU} / \mathrm{kg} /$ twice daily or $200 \mathrm{IU} / \mathrm{kg} /$ day SC $[10,11]$ are also used. Moreover, oxygen therapy as well as slow fluid intake, no more than $500 \mathrm{ml}$, should be ordered, and in patients with low cardiac output it is desirable to use the infusion of catecholamines (dopamine, dobutamine). International normalized ratio (INR) monitored oral anticoagulant treatment has to be continued for at least 3-6 months in patients after an acute embol- ic incident, whereas if there is a contraindication to anticoagulants patients should continue on low molecular weight heparins (LMWHs) $[5,6,12,13]$.

\section{Prognosis}

In patients with the diagnosis and standard treatment of PE the mortality rate is $2-8 \%$, rising to about $30 \%$ in patients not treated, mainly due to the lack of correct diagnosis. Some patients with PE present in a serious condition, with very severe symptoms, shock or hypotension, and the mortality in these patients reaches $30-35 \%$. In contrast, in patients without hypotension prognosis is determined on the basis of echocardiography, and the absence of right ventricular overload is a positive prognostic factor. The choice of treatment in the acute phase of the disease depends on the assessment of prognosis, defined on the basis of clinical status. In patients without symptoms of shock and without significant systemic hypotension biochemical indices of heart damage and cardiac overload should be measured as a basis for prognosis [11].

Factors that increase the risk of death in the acute phase include right ventricular failure (HR 2.4, 95\% Cl 1.5-3.7), hemorrhagic complications following thrombolytic therapy or anticoagulation, subsequent embolic episode, and comorbidities, especially cancer (HR 2.3, 95\% CI 1.5-3.5) [14].

The risk of recurrent PE is highest within 4-6 weeks after the first thromboembolic episode, but effective treatment reduces it to $8 \%$ [14].

\section{Discussion}

Oncological treatment such as radiotherapy, chemotherapy and hormone therapy increases the risk of thrombosis and embolism, among other things due to the release of procoagulants and cytokines from cancer cells as well as the toxic effect acting on the vascular endothelium, and the reduction in the concentration of natural anticoagulants [15-17].

With the introduction of intensive chemotherapeutic regimens an increase in thrombotic microangiopathy is observed, affecting a growing number of patients after highdose chemotherapy combined with autologous or allogeneic transplantation of hematopoietic cells $[18,19]$. The estimated incidence of this syndrome is 2 to $8 \%$ of patients treated with systemic therapy. It generally appears 2-9 months after the completion of chemotherapy when the cancer itself is in remission. In previous years this syndrome was associated with the use of mitomycin C, but now it occurs after a number of other chemotherapeutic agents. It is influenced not only by the nature of the cytotoxic drug, but also by the single and total dose. Radiotherapy alone increases the predisposition to the occurrence of thromboembolic disease, and chemotherapy combined with radiation of the whole body has an additive effect [15]. It is also known that the use of cyclosporin $A$ is associated with a higher occurrence of thrombotic microangiopathy. The prognosis for this complication is poor and mortality is about 31\%. What is more, in patients who survive there is often permanent or even progressive renal failure. Based on studies of different authors, it is presumed that the mechanism of the pathogenesis of this process is chemotherapy-induced damage to the vas- 
cular endothelium. Levine et al. conducted a prospective study in patients with stage IV breast cancer. One group of patients undergoing chemotherapy received warfarin at a dose of $1 \mathrm{mg}$ per day; the other group was placebo-treated. The author demonstrated a relative risk reduction of venous thromboembolism (VTE) by $85 \%(p=0.031)$ with no statistically significant effect on the incidence of bleeding [13, 20]. Despite the results of this study oncologists do not use universal prophylaxis with oral anticoagulants in the course of chemotherapy, mainly because of the potential risk of bleeding, the logistics of laboratory monitoring and modification of doses, which are necessary due to the changes in the number of platelets and interactions with other concomitant medications.

On the other hand, so far there has been no evidence of increased incidence of thrombophilia in patients with cancer. It is well known that thromboembolic disease in patients with cancer occurs in advanced disease and is associated with poor prognosis [13]. Studies indicate that the incidence of acquired resistance to activated protein $C$ is higher in cancer patients than in patients without cancer. The phenomenon of resistance to activated protein C, which is the most common cause of acquired thrombophilia, was first described by Dahlback [1]. In the author's opinion it is associated with factor $V$ Leiden mutation. Bloom et al. conducted a retrospective study among 1267 patients with a first event of thromboembolism or venous thrombosis and found that factor $\vee$ Leiden mutation in patients with cancer increased the risk of thromboembolic complications by 2.7 times [2]. Another cause of thromboembolic events may be a correlation between cancer and antiphospholipid antibodies (APA). In patients with solid tumors and with increased levels of antibodies against cardiolipin the incidence of thromboembolic events was $28 \%$ compared to $14 \%$ in patients who show no evidence of increased concentration of anticardiolipin antibodies, $p<0.05$ [21]. Another factor predisposing to arterial thrombosis is hyperhomocysteinemia, which may result from congenital defects in the enzymes but also acquired diseases such as breast cancer, ovarian cancer, pancreatic cancer and acute lymphoblastic leukemia. The literature mentions a number of other conditions that may significantly influence the processes of coagulation in patients with cancer, but the exact mechanism is not completely understood and research on the pathomechanism of this phenomenon is still carried out.

Venous thromboembolism is common in patients with any cancer and the incidence is increased by surgery, chemotherapy, radiotherapy and disease progression. In many studies the authors found that pre-treatment abnormalities of coagulation in patients with cancers were significantly correlated with survival. Low molecular weight heparin has been used for over 20 years in the prophylaxis of VTE and has been shown to be the drug of choice in the treatment of VTE in cancer patients. However, there are limited data on the use of LMWH in primary thromboprophylaxis in cancer patients and this is reflected in the difference in practice amongst oncologists. A recent survey showed that many oncologists do not recognize the thrombogenic effects of treatment for cancer and that thromboprophylaxis is rarely used [14].

\section{Summary}

In the daily practice of medical oncology treatment of patients with a diagnosis of thromboembolism is not rare. Due to the focus on anticancer therapy the possibility of health deterioration or even imminent danger to life caused by thromboembolic disease may be underestimated. The deterioration of the patient in these cases is interpreted as a failure of therapy, complication after oncological treatment or progression of cancer. Ignorance of the symptoms of lifethreatening condition makes it impossible to establish the correct diagnosis, resulting in the lack of timely implementation of appropriate treatment. The priority of treatment for cancer might result in overlooking the symptoms that are the real cause of the poor effect of the anticancer therapy. Managing the patient with cancer is difficult and therefore oncologists must plan the treatment with utmost care and attention, bearing in mind the possible occurrence of venous thromboembolism during diagnostic tests and implemented oncological treatment.

\section{The authors declare no conflict of interest.}

\section{References}

1. Dahlbäck B, Carlsson M, Svensson PJ. Familial thrombophilia due to a previously unrecognized mechanism characterized by poor anticoagulant response to activated protein C: prediction of a cofactor to activated protein C. Proc Natl Acad Sci U S A 1993; 90: 1004-8.

2. Bloom J, Doggen C, Rosendaal F. The risk of venous thrombosis in cancer patients with or without the factor $V$ Leiden mutation. Haemostasis 2001; 31: 73.

3. Biedka M, Makarewicz A, Makarewicz R, Ziółkowska E. Choroba zakrzepowo-zatorowa w przebiegu choroby nowotworowej. Onkol Radioter 2012; 3: 43-51.

4. Lugassy G, Falanga A, Kakkar A, Rickles F. Zakrzepica a nowotwory. Wyd. Medipage, Warszawa 2006; 1-255.

5. Ziółkowska E. Wpływ leczenia energia promienista na układ fibrynolityczny osocza chorych na raka płuca. Rozprawa doktorska, Akademia Medyczna im. Ludwika Rydygiera w Bydgoszczy, 1999; 9-10.

6. Jassem E. Zatorowość płucna. Polska Medycyna Paliatywna 2003; 2: 93-8.

7. Budaj A. Ostra zatorowość płucna - jak rozpoznawać, leczyć i skutecznie zapobiegać innym epizodom. Przew Lek 2007; 7: 53-61.

8. Lake DR, Kavanagh JJ, Ravenel JG, Schoepf UJ, Costello P. Computed tomography an pulmonary embolus: a review. Semin Ultrasound CT MR 2005; 26: 270-80.

9. Ravenel JG, Kipfmueller F, Schoepf UJ. CT angiography with multidetector-row CT for detection of acute pulmonary embolus. Semin Roentgenol 2005; 40: 11-9.

10. Capstick T, Henry MT. Efficacy of thrombolytic agents in the treatment of pulmonary embolism. Eur Respir J 2005; 26: 864-74.

11. Dolovich LR, Ginsberg JS, Douketis JD, Holbrook AM, Cheah G. A metaanalysis comparing low-molecular-weight heparins with unfractionated heparin in the treatment of venous thromboembolism: examining some unanswered questions regarding location of treatment, product type, and dosing frequency. Arch Intern Med 2000; 160: 181-8.

12. Quinlan DJ, McQuillan A, Eikelboom JW. Low-molecular-weight heparin compared with intravenous unfractionated heparin for treatment of pulmonary embolism: a meta-analysis of randomized, controlled trials. Ann Intern Med 2004; 140: 175-83. 
13. Lee AY, Levine MN, Baker RI, et al. Low-molecular-weight heparin versus a coumarin for the prevention of recurrent venous thromboembolism in patients with cancer. N Engl J Med 2003; 349: 146-53.

14. Griffiths GO, Burns S, Noble SI, Macbeth FR, Cohen D, Maughan TS. FRAGMATIC: a randomized phase III clinical trial investigating the effect of fragmin added to standard therapy in patients with lung cancer. BMC Cancer 2009; 9: 355.

15. Pruszczyk P, Gacionga Z. Żylna choroba zakrzepowo-zatorowa w praktyce lekarskiej. Medycyna po Dyplomie 2005; 9: 3-32.

16. Fox AD, Banning AP, Channon K, Hands L. Saddle embolus of the carotid bifurcation. A late complication of mediastinal radiotherapy. Eur I Vasc Endovasc Surg 1999; 17: 360-2.

17. Ziółkowska W, Biedka M, Wiśniewski T, Makarewicz A, Makarewicz T, Żmuda E. Zatorowość płucna w przebiegu raka żołądka. Onkol Radioter 2011; 2: 36-43.

18. Batra R, Davies JN, Wheatley D. Extensive arterial and venous thrombo-embolism with chemotherapy for testicular cancer: a case report. Cases J 2009; 2: 9082.

19. Stine KC, Saylors RL, Saccente CS, Becton DL Treatment of deep vein thrombosis with enoxaparin in pediatric cancer patients receiving chemotherapy. Clin Appl Thromb Hemost 2007; 13: 161-5.

20. Fox AD, Banning AP, Channon K, Hands L. Saddle embolus of the carotid bifurcation. A late complication of mediastinal radiotherapy. Eur I Vasc Endovasc Surg 1999; 17: 360-2.

21. Zuckerman E, Toubi E, Golan TD, Rosenvald-Zuckerman T, Sabo E, Shmuel Z, Yeshurun D. Increased thromboembolic incidence in anticardiolipin positive patients with malignancy. Br J Cancer 1995; 72: 447-51.

\section{Address for correspondence}

dr n. med. Marta Biedka

Oddział Radioterapii I

Centrum Onkologii im. F. Łukaszczyka

I. Romanowskiej 2

85-796 Bydgoszcz

phone +48 523743374

e-mail: martabiedka@tlen.pl

Submitted: 28.03 .2011

Accepted: 17.07.2012 